\title{
DIGITAL PRINTABILITY OF PAPERS MADE FROM INVASIVE PLANTS AND AGRO-INDUSTRIAL RESIDUES
}

\author{
IGOR KARLOVITS, ${ }^{*}$ URŠKA KAVČIČ, ${ }^{*}$ GREGOR LAVRIČ, ${ }^{*}$ ANDREJ ŠINKOVEC ${ }^{*}$ and \\ VLADIMIR ZORIĆ ${ }^{* *}$ \\ *Pulp and Paper Institute, Ljubljana, Slovenia \\ *Faculty of Technical Sciences, University of Novi Sad, Novi Sad, Serbia \\ 区 Corresponding author: I. Karlovits, igor.karlovits@icp-lj.si
}

Received March 30, 2020

\begin{abstract}
The use of an alternative fibre source for papermaking encourages more circular material streams with a focus on local harvesting and a lesser demand for large-scale pulping. The changes in the printing industry with the advent of digital printing technologies, such as electrophotography and ink-jet, demand that the paper should have appropriate printability. Digital printability depends on the printing machine, toner and paper. In this study, we tested six different papers made from invasive plants, namely, Japanese knotweed, black locust, Canadian goldenrod, and agro-industrial residues, such as miscanthus, tomato stems and waste jute bags. The papers were printed by electrophotography printing, and optical print quality parameters, such as optical density, printing unevenness and print gloss, as well as surface roughness and surface resistivity, were measured. The results indicate that average surface roughness and grammage have a high linear correlation with print gloss, and a moderate one with print density. The mottling values of prints have inconsistencies with the surface roughness values because of the specific fiber orientation based structure.
\end{abstract}

Keywords: invasive plants, agro-waste, printability, surface properties, digital printing

\section{INTRODUCTION}

Because of an increased demand for paperbased products, especially in the packaging sector, sustainable paper production and printing are in pressing need for new types of fibre sources suitable for papermaking. ${ }^{1-5}$ Alternative fibres (or non-wood fibres) are mainly grouped into four categories: on purpose dedicated crops, agricultural residues, industrial residues and naturally occurring uncultivated crops. ${ }^{6}$ Considering classic alternative fibre solutions, which can be easily associated with the four major groups, there are some trends in using plants that are not naturally occurring, such as invasive ones. Invasive plant species are species that are not native to a specific geographical location and have the tendency to spread to a degree believed to cause damage to the environment, social economy or human health. Other non-wood fibres, such as jute, can come in many forms, as many products are made from it, but can also result as industrial waste from coffee plants in the form of waste coffee bags. All of these plants, of course, do not have the yield of hardwood or softwood species for massive papermaking production, but using them can provide a good raw material base for smaller paper plants, which, through local supply chains, make the process more sustainable and circular.

A large portion of the produced paper and related paper-based products are printed, and, besides mechanical properties, the printing properties of these materials are also important. Runnability and printability are two main parameters that define the extent to which the paper is used in the printing and converting industry. Due to the digitalization and decline of some paper product markets (newspaper printing), digital printing technologies, such as electrophotography and ink-jet, are overtaking large parts of the printing markets from other printing technologies. The combination of nonwood fibres and short print run capable digital printing machines can provide an excellent solution to sustainability.

Electrophotography is one of the most commonly used non-impact printing technologies. It applies powder and liquid toners, which are transferred to mostly paper substrates directly or 
through some intermediate systems, such as drums or belt. For transporting the charged toner particles, electrostatic forces are needed, with the help of the contact pressure between the imaging drum and the paper. The subsequent step is fixation, where heath and contact pressure ensures better bonding of the toner to the paper. ${ }^{7}$ Studies on the printability of papers in electrophotography have found that paper properties, such as brightness, opacity, print gloss, density and surface roughness, have equal importance for final visual and measured print quality. ${ }^{8-10}$ Also, paper samples with higher softwood fibre percentage (i.e. fibres with wider diameter) and uneven toner coverage will increase surface roughness, which contributes to a lower-quality visual appearance. This effect happens because toner particles tend to be trapped in-between the broader gaps of the overlapping fibres and the heat transfer between the toner particles trapped in the underlying fibres and the fuser roll tends to be weaker. ${ }^{11}$ Before the toner is fused on the surface, low-frequency roughness, that is, roughness larger than the size of the toner particles distributed over the unfused surface, is characteristically similar to that of the paper surface. The pressure and the heat applied to the toner provide a toner layer with a shape different from that of the paper surface topography through processes such as coalescence and flow. ${ }^{12}$ This is especially vital in uncoated papers where the chemical and mechanical toners with sizes of 3-15 $\mu \mathrm{m}$ are transferred to the rough surface of uncoated papers (Fig. 1).

The dependence and the variation of gloss and micro-gloss, as well as other print quality parameters, on the surface roughness of woodbased papers have been examined by white light interferometers $^{13}$ and stylus profilometers. ${ }^{11}$ Mottling or print unevenness is caused by paper properties, more precisely, optical, absorption and chemical properties, for the classic printing techniques, where ink vehicle absorption is present. In digital printing, where this effect is small, the print mottle is usually the effect of uneven moisture in the paper and microroughness variations. The texture analysis using the Gray-Level Co-Occurrence Matrix (GLCM) was found to be very useful in the past for print unevenness analysis. ${ }^{14-17}$ One more critical quality factor, besides surface texture, consists in the electric and dielectric properties of the print substrates. The surface and volume resistivity of paper are strongly dependent on the electric field strength, and this dependence is influenced by the thickness, density and filler content of the paper. ${ }^{18}$ Testing of non-wood papers has been done for some types of papers and printing technologies (such as UV ink-jet technology or offset printing) ${ }^{19-21}$ and the test results appeared promising, for example, for sensor printing. ${ }^{22}$

\section{EXPERIMENTAL}

\section{Materials and methods}

All the paper types were produced at the Pulp and Paper Institute in Ljubljana, Slovenia, on a pilot paper machine. The fibres were obtained from different sources: invasive plant species, obtained by urban harvesting, and planned to harvest plants (miscanthus and tomato stems). At the same time, jute bags that had been used for transporting coffee were upcycled as a fibre source for papermaking. Plant fibres were delignified and processed for papermaking. Cationic starch, surface sizing and some fillers were added to gain basic printability properties. The primary material properties of the tested papers are presented in Table 1. Table 2 presents the measured width and lengths of the invasive plants and residue fibres used in making the papers.

For printing, a Xerox Versant 80 Press electrophotography printer, with original toners, was used. The printing was done with a calibration curve for uncoated papers, as all the papers used had no coatings and there was no colour space simulation to maximize the influence of the papers on the optical properties. The optical density of papers was measured using an i1Pro spectrophotometer, with black backing, according to ISO 5-3 standard. For the evaluation of printing unevenness (mottling), the printed samples were scanned (Canon CanoScan 5600 flatbed scanner), with $100 \%$ black toner colour patches (300 PPI), and the GLCM method was used in the R software using the radiomics library.

Print gloss was evaluated using a Rhopoint IQ triangle glossmeter, according to the standard ISO 2813:2014. Surface roughness was measured with a KR220 handheld stylus profilometer to derive surface roughness parameters $R_{a}, R_{p}, R_{v}$ (ISO 4287:1994). The surface resistivity of paper was measured in a controlled humidity environment, with an Agilent 43339B High Resistance Meter and a 160008B Resistivity Cell. All the paper samples were conditioned in standard atmosphere, according to ISO 187:1990 before every test.

\section{RESULTS AND DISCUSSION}

\section{Surface roughness of papers and prints}

The surface roughness of papers was measured with a KR220 stylus profilometer, with a diamond tip, and cut-off of $2.5 \mathrm{~mm}$. A Gauss profile filter was used to filter the data. The surface roughness 
parameters were determined by measuring in the machine direction and in cross-direction, on 5 spots on five paper samples. The average surface roughness is presented in Figure 2.

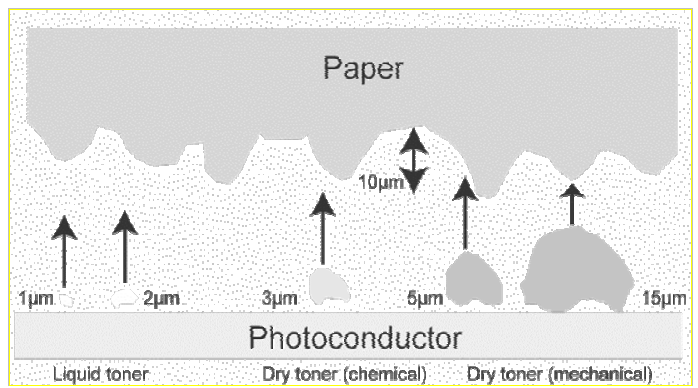

Figure 1: Toner transfer to uncoated papers in electrophotography

Table 1

Primary materials used for preparing papers in this study

\begin{tabular}{lcccccc}
\hline Parameter & Jute & Miscanthus & $\begin{array}{c}\text { Canadian } \\
\text { goldenrod }\end{array}$ & $\begin{array}{c}\text { Black } \\
\text { locust }\end{array}$ & $\begin{array}{c}\text { Tomato } \\
\text { stem }\end{array}$ & $\begin{array}{c}\text { Japanese } \\
\text { knotweed }\end{array}$ \\
\hline Grammage $\left(\mathrm{g} / \mathrm{m}^{2}\right)$ & 85 & 125 & 105 & 120 & 115 & 110 \\
Hardwood pulp $(\%)$ & 32.5 & 0 & 27.5 & 30 & 40 & 30 \\
Softwood pulp (\%) & 32.5 & 33 & 27.5 & 30 & 40 & 30 \\
Freeness of pulp (SR) & 27 & 25 & 25 & 25 & 27 & 25 \\
Alternative fibers (\%) & 35 & 67 & 45 & 40 & 20 & 40 \\
Cationic starch (\%) & 1 & 0.75 & 1 & 1 & 1 & 1 \\
Fillers (\%) & 10 & 0 & 10 & 10 & 5 & 10 \\
Surface sizing (\%) & 3 & 2 & 3.5 & 3.5 & 4 & 3 \\
\hline
\end{tabular}

Table 2

Width and length of alternative fibres

\begin{tabular}{lcc}
\hline Fibre type & Length $(\mathrm{mm})$ & Width $(\mu \mathrm{m})$ \\
\hline Jute & 1.02 & 20.55 \\
Miscanthus & 0.54 & 15.70 \\
Canadian goldenrod & 0.45 & 13.85 \\
Black locust & 0.96 & 13.77 \\
Tomato stem & 0.48 & 24.83 \\
Japanese knotweed & 0.78 & 18.66 \\
\hline
\end{tabular}

From Figure 2, we can observe that the paper made from waste jute bags had the smallest average roughness, with an average value of 4.77 $\mu \mathrm{m}$, and the print roughness with the value of $R_{a}$ $=3.37 \mu \mathrm{m}$. The highest average $R_{a}$ value for paper was recorded on the paper made from black locust, while the highest average $R_{a}$ value for prints, of $6.83 \mu \mathrm{m}$, was noted on the paper made from tomato stems. All the prints had lower average roughness than those of papers, which indicates that the toner levelled out some of the paper's surface roughness. If we calculate the differences between average values, we can see that they differ from $0.69 \mu \mathrm{m}$, for tomato stems, to $1.82 \mu \mathrm{m}$, for Canadian goldenrod. The levelling of the toner during fusion on the paper topography can be evaluated by observing the differences in the $R_{p}$ and $R_{v}$ values (peaks and valleys). The results are presented in Table 3 .

From the data in Table 3, we can see differences in the levelling of toner on different samples, which have surface topography changes in the forms of peaks and valleys. The papers from tomato stems and Japanese knotweed had the highest differences for the valleys, which indicates filling of the fibre surface valleys with toner. Other papers had higher values for peak differences, which shows the toner covered mostly the peaks. This levelling is controlled by the local topography, which, in the case of these 
papers, with no surface coating and with biomass particles (such as impurities), can be different. The black locust paper had high ridges owing to particles, which were covered, and fewer valleys, and it presented similar values as the papers with lower average surface roughness.

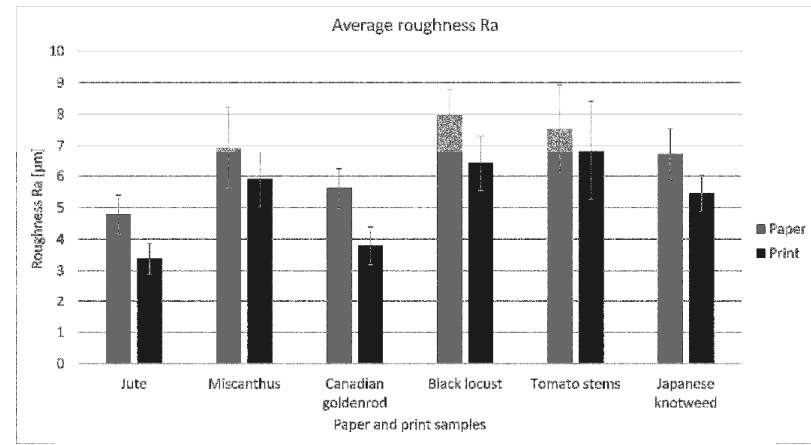

Figure 2: $R_{a}$ surface parameter of measured papers and prints

Table 3

Differences in profile peaks and valleys of printed papers

\begin{tabular}{lll}
\hline Paper sample & $\Delta \mathrm{R}_{\mathrm{p}}$ & $\Delta \mathrm{R}_{\mathrm{v}}$ \\
\hline Jute & 5.26 & 1.64 \\
Miscanthus & 5.50 & 1.41 \\
Canadian goldenrod & 6.27 & 1.48 \\
Black locust & 7.93 & 1.96 \\
Tomato stems & 3.63 & 3.90 \\
Japanese knotweed & 6.21 & 4.19 \\
\hline
\end{tabular}

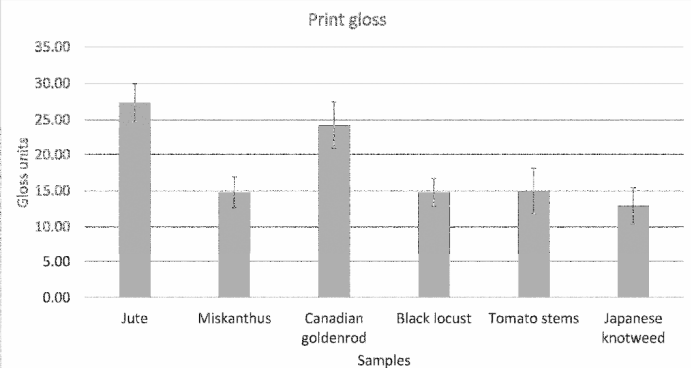

Figure 3: Print gloss values of printed samples

\section{Print gloss}

The print gloss was measured on five samples in the machine direction, and cross-direction orientation on $100 \%$ black toner colour printed patches. The values are presented in Figure 3. As can be observed, the prints made on jute paper had the largest print gloss, with the average value of 27.33, while the Japanese knotweed paper had the lowest print gloss, with an average value of 12.91. Miscanthus, black locust and tomato stem prints had similar values, while the Canadian goldenrod ones had the second-largest print gloss value.

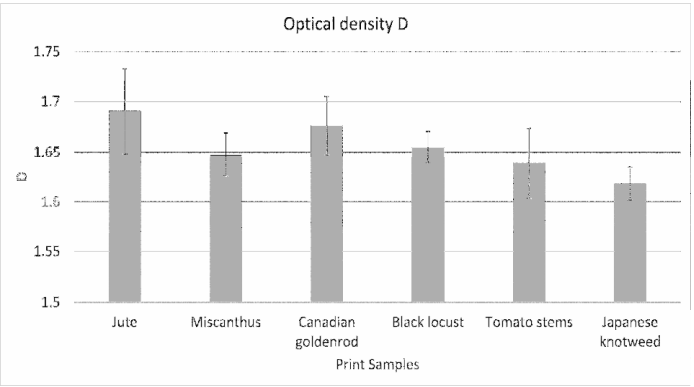

Figure 4: Average optical densities of black printed samples

When comparing the average roughness value with print gloss, an excellent negative linear correlation $(\mathrm{r}=-0.90)$ is observed. Considering basic paper properties, grammage had an excellent linear correlation with specular gloss, with $r=0.83$.

\section{Optical density}

Optical density was measured on $100 \%$ black toner colour patches of five samples, on 20 measurement spots. The average values are shown in Figure 4. The highest optical density was measured on the printed jute paper, with an 
average of 1.69 , and the lowest one was recorded for the Japanese knotweed sample, with a value of 1.61 .

\section{Print unevenness (mottling)}

The printing unevenness (mottling) was evaluated by second-order statistical texture parameters GLCM: contrast, correlation, dissimilarity, entropy and homogeneity. The calculation of the parameters was done in 4 angles $\left(0^{\circ}, 45^{\circ}, 90^{\circ}, 135^{\circ}\right)$, with an offset of 1 pixel. All images were turned to grayscale, and the GLCM matrix was determined.

The contrast value defines the intensity contrast between a pixel and its neighbour over the whole image, where the value 0 represents a constant image. The correlation value shows how correlated a pixel is to its neighbour over the whole image. The dissimilarity is the variation of grey-level voxel pairs. Entropy is the measure of randomness, while homogeneity defines the measure of closeness of the distribution of elements in the GLCM to the GLCM diagonal. As all the samples were uncoated and had distinctive textural features due to the structures of the fibres used, this kind of more detailed texture analysis was needed. The results for the GLCM contrast are shown in Figure 5. All GLCM texture values calculated are unitless. The smallest contrast value was found for the Canadian goldenrod paper sample, while the largest - for the Japanese knotweed paper. Also, the papers with lower values had a lower variation of minimal and maximal values. As the analysis was made in four

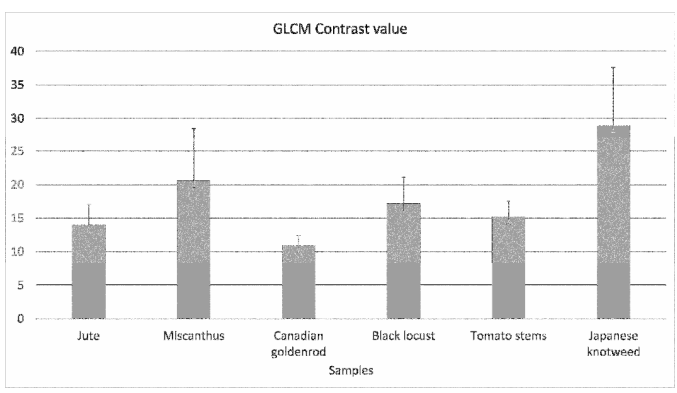

Figure 5: GLCM contrast value of measured samples directions, the most substantial variations came from the direction of the paper formation.

In Figure 6, the values for the other parameters are presented. Entropy has a high value when all pixel elements are equal; here, it can be observed that the jute and Canadian goldenrod papers have the smallest values and Japanese knotweed and miskanthus - the highest ones. The dissimilarity value exhibits a similar trend, with differences in black locust and tomato stems. Dissimilarity is a measure of local intensity variation and defines the mean absolute difference between the neighbouring pairs. A higher value correlates with a more significant disparity in intensity values among neighbouring voxels. Here, the Japanese knotweed and miskanthus had the most significant standard deviation and mean values, which indicate lots of local intensity variation on the surface. Interestingly, the homogeneity value gives higher numbers if the big numbers are on the diagonal, and the Japanese knotweed reached here the smallest value, which indicates a different formation shape of the basic paper.

\section{Surface and volume resistivity}

The surface and volume resistivity was measured after all the paper samples were conditioned. The high resistivity cell had a measuring electrode of $50 \mathrm{~mm}$ diameter. The following measurement parameters were used: 5 $\mathrm{kg}$ sample clamping, $500 \mathrm{~V}$ voltage and $60 \mathrm{~s}$ charging time. The results are presented in Figure 7.

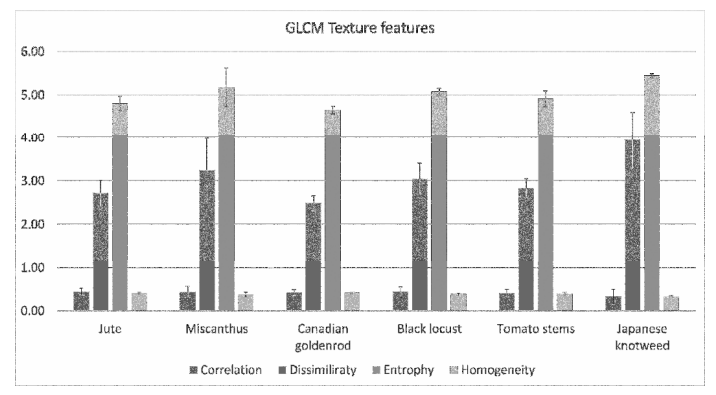

Figure 6: GLCM texture features of printed samples 


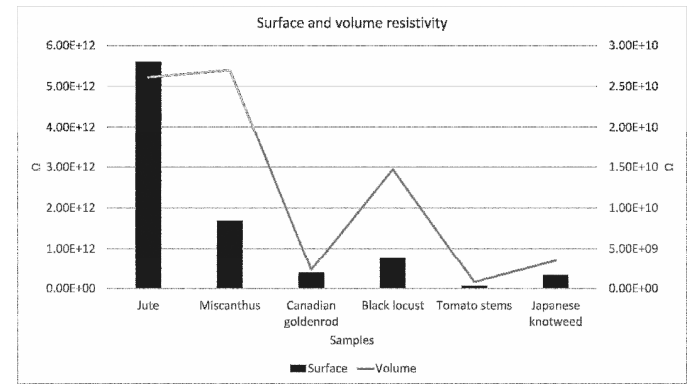

Figure 7: Surface and volume resistivity of paper samples at $50 \% \mathrm{RH}$

From Figure 7, it can be seen that the miscanthus and jute samples had the most substantial volume resistivity, while the Canadian goldenrod sample - the smallest value. Surface resistivity was higher for the samples containing longer alternative fibres, but showed small differences among samples. The jute paper was an exception, exceeding $5 \mathrm{E}+10^{12} \Omega$, which is beyond the values recommended for uncoated papers to be used for electrophotography printing.

\section{CONCLUSION}

The present study allowed drawing a number of conclusions. When comparing the data obtained for different material properties, it may be noted that the average roughness values have an excellent negative linear correlation with print gloss $(\mathrm{r}=-0.90)$ and a moderate negative correlation with optical density values $(r=-0.57)$. Considering the basic paper properties, grammage had an excellent linear correlation with specular gloss, with the value of $r=0.83$. Surface resistivity, which is related to the optical density value, shows no clear correlation - apart from the waste jute bag paper, all other papers had similar values. Grammage and surface resistivity have an excellent negative linear correlation, with the value of $r=-0.73$. Nevertheless, the paper with the highest surface and volume resistivity had the highest optical density values. Mottling, calculated by second-order statistical parameters, showed less consistency with the average $R_{a}$ values, as the Japanese knotweed paper exhibited the most significant contrast values. Contrast is sensitive to diagonal orientation, and the inconsistency can be caused by fibre properties (length and width positioning and formation with the rest of the pulp). This effect has been concluded from the most considerable sum of the peak and valley differences on the surface, for example, black locust has longer and narrower fibres than most of the other non-wood fibres used and recorded the highest peak-valley difference. These differences caused high surface roughness, but toner levelling decreased the differences, as indicated by the dissimilarity and entropy values. Also, the offset value (80 microns) for the calculation of the matrix is more sensitive to smaller changes (micro-roughness) than to those that influence optical properties (macro-roughness). Gloss and optical density presented high to moderate linear correlation with the average surface roughness. In contrast, surface and volume resistivity had a smaller impact on optical density and other optical properties. The grammage of the uncoated papers was reversibly correlated with their optical properties, as the smallest grammage paper had the best optical properties. This result is explained by the number and type of irregular fibres used in paper formation.

To conclude, such types of papers are suitable for achieving excellent electrographic digital printing quality in uncoated paper segments. Also, it should be pointed out that the runnability (adhesion and friction properties) should be adjusted to the requirements.

ACKNOWLEDGEMENT: We want to thank Tea Kapun and the project APPLAUSE "From harmful to useful with citizen's led activities", cofinanced by the European Union under the European Regional Development Fund, through the initiative Urban Innovative Actions, for providing alien plant species papers.

\section{REFERENCES}

1 Z. Daud, M. Z. Mohd Hatta, A. S. Mohd Kassim, H. Awang and A. Mohd Aripin, BioResources, 9, 872 (2014), https://doi.org/10.15376/biores.9.1.872-880 
2 R. Khiari, E. Mauret, M. N. Belgacem and F. Mhemmi, BioResources, 6, 265 (2011), https://bioresources.cnr.ncsu.edu/wpcontent/uploads/2016/06/BioRes_06_1_0265_Khiari_ MBM_Tunis_Date_Palm_Fibers_Paper_Appl_1134.pd

J. D. Robles, E. E. Victor, M. Del Valle Palenzuela Ruiz, M. E. Eugenio Martín, A. R. Pascual et al., Cellulose Chem. Technol., 54, 73 (2020), https://doi.org/10.35812/CelluloseChemTechnol.2020. 54.08

A. K. Sharma, R. Godiyal and B. Prakash Thapliyal, Cellulose Chem. Technol., 53, 747 (2019), https://doi.org/10.35812/CelluloseChemTechnol.2019. 53.73

5 T. Kapun, A. Šinkovec, J. Zule, M. Skodlar and G. Lavrič, in Procs. of $1^{\text {st }}$ CPC, 2019, p. 204, https://doi.org/10.5281/zenodo.3430998

6 M. Finell, Ph. D. Thesis, Swedish University of Agricultural Sciences, Umea, 2003

H. Kipphan, "Handbook of Print Media", Springer, Verlag, 2001, p. 60, https://doi.org/10.1007/978-3-54029900-4

8 S. Chen, Master's Thesis, Department of Chemical Engineering and Applied Chemistry, University of Toronto, Toronto, 2009

9 C. B. Duke, J. Noolandi and T. Thieret, Surf. Sci., 500, 1005 (2002), https://doi.org/10.1016/s00396028(01)01527-8

10 S. Bauk, I. Majnarić, S. Bolanča and K. Golubović, in Procs. $12^{\text {th }}$ PDC Conference, 2008, p. 41, https://www.bib.irb.hr/366576/download/366576.bauk _majnaric_bolanca.pdf

${ }_{11}$ S. Chen, R. Farnood, N. Yan, S. Di Risio and J. Song, Nord. Pulp Pap. Res. J., 27, 729 (2012), https://doi.org/10.3183/npprj-2012-27-04-p729-738
12 Y. Kitano, T. Enomae and A. Isogai, J. Imaging Sci. Techn., 52, 10504-1 (2008), https://doi.org/10.2352/j.imagingsci.technol.(2008)52: 1(010504)

${ }_{13}$ M. Juuti, T. Prykari, E. Alarousu, H. Koivula, M. Myllys et al., Colloid Surface A., 299, 101 (2007), https://doi.org/10.1016/j.colsurfa.2006.11.039

14 T. Pettersson, Master's Thesis, Royal Institute of Technology, Stockholm, 2004

15 I. Jurič, I. Karlovits, D. Novaković and I. Tomić, Color Res. Appl., 41, 493 (2016), https://doi.org/10.1002/col.21984

16 A. Hladnik and M. Lazar, Nord. Pulp Pap. Res. J., 26, 99 (2011), https://doi.org/10.3183/npprj-2011-2601-p099-105

17 I. Karlovits, J. Juhant Grkman, D. Ravnjak and G. Lavrič, in Procs. $44^{\text {th }}$ IARIGAI Conference, Freibourg, 2017, p. 187, https://iarigai.com/wpcontent/uploads/2019/09/Advances-Vol442017_online.pdf

18 P. Sirviö, Ph. D. Thesis, Åbo Akademi University, Åbo, 2016

19 I. Plazonic, I. Bates and Z. Barbaric-Mikocevic, BioResources, 11, $5033 \quad$ (2016), https://doi.org/10.15376/biores.11.2.5033-5049

20 G. Lavrič, T. Pleša, A. Mendizza, M. Ropret, I. Karlovits et al., in Procs. $9^{\text {th }}$ GRID Symposium, 2018, p. 99, https://doi.org/10.24867/grid-2018-p11

I. Bates, I. Plazonić, K. Petric Maretić, M. Rudolf and V. Radić Seleš, in Procs. $3^{\text {rd }}$ IPS Symposium, 2019, p. 287, http://www.printistanbul.org/2019/wpcontent/uploads/2020/01/Printistanbul_Bildiri_Kitabi_ 2019_S.pdf

22 U. Kavčič and I. Karlovits, Nord. Pulp Pap. Res. J., in print (2020), https://doi.org/10.1515/npprj-20190070 